\title{
Student Skill and Goal Achievement in the Mapping with Google MOOC
}

\author{
Julia Wilkowski \\ Google \\ 1600 Ampitheatre Pkwy \\ Mountain View, CA 94041 \\ wilkowski@google.com
}

\author{
Amit Deutsch \\ Google \\ 1600 Ampitheatre Pkwy \\ Mountain View, CA 94041 \\ amitdeutsch@google.com
}

\author{
Daniel M. Russell \\ Google \\ 1600 Ampitheatre Pkwy \\ Mountain View, CA 94041 \\ drussell@google.com
}

\begin{abstract}
Students who registered for the Mapping with Google massive open online course (MOOC) were asked several questions during the registration process to identify prior experience with eleven skills as well as their goals for registering for the course. Students selected goals from a list; they were periodically reminded of these goals during the MOOC. At the end of the course, we compared students' self reports of goal achievement on a post-course survey with behavioral click-stream analysis. In addition, we assessed how well prior skill in a subject predicts a student's course completion and found no correlation. Our research shows that students who completed course activities were more likely to earn certificates of completion than peers who did not.
\end{abstract}

\section{Author Keywords}

MOOCs; Google; Skills; Goals; Activities

\section{ACM Classification Keywords}

K.3.1 Computer Uses in Education: Distance learning

\section{INTRODUCTION}

Google, Inc. has been experimenting with MOOCs to teach members of the general public how to use Google tools more efficiently and effectively. The Course Builder opensource platform emerged and has evolved from this research; a growing community of educators has used this tool to launch over fifty MOOCs worldwide. The course development team consists of Google employees including a program manager, instructional designers, engineers, content experts, and videographers. A primary criticism of MOOCs is that their completion rate is very low, approximately $10 \%[11,12]$. Google's course development team (and MOOC community as a whole) frequently discusses how to measure course "success" $[8,9]$.

We learned through two of Google's previous courses, Power Searching and Advanced Power Searching with

Permission to make digital or hard copies of part or all of this work for personal or classroom use is granted without fee provided that copies are not made or distributed for profit or commercial advantage and that copies bear this notice and the full citation on the first page. Copyrights for thirdparty components of this work must be honored. For all other uses, contact the Owner/Author. Copyright is held by the owner/author(s).

L@S 2014, March 4-5, 2014, Atlanta, Georgia, USA

ACM 978-1-4503-2669-8/14/03.

http://dx.doi.org/10.1145/2556325.2566240
Google, that registrant of these non-university, professional development MOOCs have varying goals. Many MOOC students are well-educated professionals seeking to gain practical skills to improve their work or lives and not necessarily to earn course credits toward a degree [4]. We assert that success does not necessarily equate to students finishing the course. We believe that it is more important for students to achieve their goals, even if their primary goal is simply to learn one or two new skills. Understanding student goals and course behavior has implications for course design and development. For example, if registrants intend to just learn one or two new tips, then the course design should accommodate students' jumping directly to specific parts of the course instead of gating material by schedule or prerequisite activities.

The examined course applies several aspects of mastery learning, including breaking a topic into smaller chunks (lessons) and joining them with individual skill-based activities that provided feedback to the students [1]. Many MOOCs interrupt videos to ask students brief multiplechoice questions to keep students engaged and enhance students' understanding of course concepts [7]. In Mapping with Google activities consisted of opportunities for students to receive instant feedback about how well they could apply skills from the course.

We conducted two observational studies to assess how well different students performed on final projects based on what skills they possessed when they registered for the course, what activities they completed during the course, and what goals they set for themselves at the beginning of the course.

This paper addresses both how students' goals at the course outset affect their completion and dropout rates as well as the effect of students' skills on their success in the course. We believe that it is more important to consider student goal and skill attainment as the more important factors in course success than percentage of students who completed the course.

In the rest of this paper, we will describe the Mapping with Google MOOC, first detailing how the MOOC was built, its goals and general design. We then discuss the various student goals that registrants defined at registration as well as data collected to measure how well students achieved those goals. We also describe what we observed about 
students' skills and activity usage throughout the course. We conclude the paper with design implications and areas of future exploration.

\section{ABOUT THE COURSE}

Mapping with Google [10] was created to teach the general public how to use Google's mapping and Google Earth products more efficiently and effectively. The course was announced and registration opened on May 15, 2013. Students could access instructional materials in the twoweek period from June 10 through June 24. Mapping with Google was made using Google's open-source Course Builder platform [5] with minor modifications to display the student's profile on the course home page and add selfevaluation calibration exercises to the final projects. In addition to standard video and text lessons, the course offered application activities for a variety of skills. Examples include using Google Maps to find directions between two points on a map, using Google Maps Engine Lite to import a csv file of locations into a map, and using Google Earth to create a tour with audio, images, videos, and panoramic views. 41,455 students registered for the course; 21,837 students (53\% of registrants) did something in the course other than register (e.g. watched a video, looked at a text lesson, attempted an activity, completed a final project).

Students could choose whether to complete a final project to earn a Google Maps certificate of completion, a Google Earth certificate of completion, or both. Final projects required students to apply skills taught in the course to create a custom map or Google Earth tour. To earn a certificate of completion, students submitted a culminating synthesis project and evaluated their own work using a rubric provided. Overall students submitted a high quality of work in these projects, as validated by course staff grading a random sample of submitted projects [13]. Additional support was provided to students via Google Groups forum categories embedded on each activity page. In addition to monitoring forum posts, teaching staff, which consisted of Google employees, periodically sent email announcements/reminders to students.

Students logged into the course using a Google account. Following the course, data about the students was extracted into JSON files using the Course Builder Extract, Transform, Load (ETL) tool. The data was extracted with the user IDs obfuscated in order to preserve user privacy.

\section{STUDENT GOALS}

Students in MOOCs have a variety of reasons for registering for courses. Because courses are offered at no cost, and there is a low barrier to entry, many students register for courses and then never return to the course. [3] Understanding why students register for courses allows course designers to categorize students by their goals and tailor course design to better serve each student.
Previous courses have also shown differences in student behaviors; several researchers have described their students in different ways. Phil Hill describes five categories of students in "Coursera-style MOOCs:" No-Shows, Observers, Drop-Ins, Passive Participants, Active Participants [6]. Other research describes four categories: Completing, Auditing, Disengaging, and Sampling [8]. Coursera's founders classify students as Passive participants, Active participants, and Community contributors (not mutually exclusive) [9]. All of these studies divide students by the behaviors they exemplify during the course. We identified four categories of students based on their stated intention of how they would interact with the course and assessed whether they achieved the goals they established.

The four categories we have observed include

1. No-shows: students register for the course (usually before the course content is available) but never log in to the course to interact with the content

2. Observers: want to see what an online course is like or how this one is taught

3. Casual learners: want to learn one or two new things, either out of curiosity or a work/school-related need

4. Completers: complete as many course elements necessary to complete projects and earn a certificate of completion

Understanding students' motivations and the relative percentages of each kind of student will help in designing future courses to help students achieve those goals. It may also influence how various learning paths are offered, such as displaying only a subset of the course to learners based on their stated preferences or previous experiences.

\section{Methods}

During registration, students were asked to complete a questionnaire about their course goals and previous experience with skills addressed in the course. The possible goals were mutually exclusive:

A. Learn new things about Google's tools in general, without necessarily completing the course.

B. Learn about a specific Google Maps feature that I need, without necessarily completing the course

C. Learn about a specific Google Earth feature that I need, without necessarily completing the course

D. Complete the requirements to earn a Google Maps certificate

E. Complete the requirements to earn a Google Earth certificate

F. Complete the requirements to earn a Google Maps and Google Earth certificate 
G. I am interested in seeing how this online course is taught and not aiming to learn about Google's mapping tools

To assess whether students achieved the goal they established, we sent them an anonymous follow-up survey as well as conducted a clickstream analysis of their behaviors. The clickstream analysis enabled us to analyze the percentage of students who selected each goal and whether their behaviors indicated that they achieved (or exceeded) those goals. For example, if a student said they want to "learn about a specific Google Maps feature that I need, without necessarily completing the course," then we assessed how many videos they watched and how many activities they completed. If they watched one video $95 \%$ of the way through, read one text lesson, and/or completed one activity, then this counted as meeting their goal. A student who selected the goal of "Learn about a specific Google Maps feature that I need, without necessarily completing the course" and ended up achieving a Google Maps certificate counted as exceeding their goal.

\section{Data}

$97 \%$ of registrants $(40,248$ out of 41,445$)$ provided a goal at registration. We discovered that $52.5 \%$ of registrants intended to complete requirements to earn a certificate; the

\begin{tabular}{|l|l|l|l|}
\hline $\begin{array}{l}\text { Intend to } \\
\text { complete }\end{array}$ & $\mathbf{5 2 . 5 \%}$ & $\begin{array}{l}\text { Do not intend to } \\
\text { complete }\end{array}$ & $\mathbf{4 4 . 7 \%}$ \\
\hline Goal F & $\begin{array}{l}40.8 \% \\
(16,891)\end{array}$ & Goal A & $\begin{array}{l}33.0 \% \\
(13,688)\end{array}$ \\
\hline Goal D & $\begin{array}{l}10.2 \% \\
(4,212)\end{array}$ & Goal B & $\begin{array}{l}5.7 \% \\
(2,364)\end{array}$ \\
\hline Goal E & $\begin{array}{l}(.5 \% \\
(604)\end{array}$ & Goal G & $\begin{array}{l}3.7 \% \\
(1,542)\end{array}$ \\
\hline & & Goal C & $\begin{array}{l}2.3 \% \\
(947)\end{array}$ \\
\hline
\end{tabular}

Table 1. Responses to goal question during registration

remaining $44.7 \%$ of registrants who supplied a goal preferred to learn a few new skills or explore the online course.

To assess students' perceptions of how well they achieved their goals, all 41,455 course registrants received an anonymous post-course survey not aligned to student identifiers in the rest of the course. 2,881 (7\%) of registrants responded to the survey. When asked, "Did you meet the goal you defined when you registered for this class?" $2,258(78 \%)$ of survey respondents indicated that they met the goal they had set at the beginning of the class. A greater percentage of students who completed the course responded to the survey compared to students who did not complete the course. Of the 1,951 students who completed the course and responded to the survey, $90.8 \%$ agreed that they met their goal. Of the 930 students who did not complete the course yet responded to the survey, 51.8\% agreed that they met their goal.

Of 20,977 engaged students (observers, casual learners, and completers who did something in the class other than register), a total of $8,890(42.4 \%)$ met or exceeded their goal via behavioral analysis. A summary of these goals can be found in Tables 2 and 3 .

\begin{tabular}{|c|c|c|}
\hline Goal & Criteria for meeting goal & $\begin{array}{l}\text { Criteria for } \\
\text { exceeding goal }\end{array}$ \\
\hline Goal A & $\begin{array}{l}\text { Satisfy the criteria for either } \\
\text { Goal B or Goal C }\end{array}$ & $\begin{array}{l}\text { Earn any } \\
\text { certificate }\end{array}$ \\
\hline Goal B & $\begin{array}{l}\text { Watch at least one entire } \\
\text { video and/or click on a text } \\
\text { lesson and/or successfully } \\
\text { complete an activity in Unit } \\
2 \text { or Unit } 3\end{array}$ & $\begin{array}{l}\text { Earn Maps } \\
\text { certificate }\end{array}$ \\
\hline Goal C & $\begin{array}{l}\text { Same as Goal B, but for Unit } \\
4 \text { or } 5\end{array}$ & $\begin{array}{l}\text { Earn Earth } \\
\text { certificate }\end{array}$ \\
\hline Goal D & $\begin{array}{l}\text { Earn Maps certificate } \\
\text { (submit and grade Maps } \\
\text { Project) }\end{array}$ & $\begin{array}{l}\text { Earn Earth } \\
\text { certificate also }\end{array}$ \\
\hline Goal E & $\begin{array}{l}\text { Earn Earth certificate } \\
\text { (submit and grade Earth } \\
\text { Project) }\end{array}$ & $\begin{array}{l}\text { Earn Maps } \\
\text { certificate also }\end{array}$ \\
\hline Goal F & $\begin{array}{l}\text { Earn Maps and Earth } \\
\text { certificates } \\
\text { (submit and grade Google } \\
\text { Maps and Google Earth } \\
\text { projects) }\end{array}$ & $\mathrm{n} / \mathrm{a}$ \\
\hline Goal G & $\begin{array}{l}\text { Fall in student category (visit } \\
\text { the course after registration } \\
\text { and click on a lesson) }\end{array}$ & $\begin{array}{l}\text { Earn any } \\
\text { certificate }\end{array}$ \\
\hline
\end{tabular}

Table 2. Criteria for Student Goal Attainment

\section{Analysis}

It is interesting to note that just over half of registrants intended to complete the course. This provides one hint to MOOCs' low completion rate: a large portion of students just wants to learn a few things. The goals with the highest attainment rate required the least amount of engagement with the course (e.g. logging in at least once after 
registering or watching one video). The goals with the lowest attainment rate required students to invest more time. The Earth and Maps projects also became available three days after the rest of the course content. Therefore students who began the class within the first three days needed to return to the site on at least one subsequent occasion. This leads us to conclude that instructors should put the most critical content at the beginning of the course as well as make important content available when the course launches.

\begin{tabular}{|c|c|c|c|}
\hline Goal & $\begin{array}{l}\text { Students } \\
\text { who selected }\end{array}$ & $\begin{array}{l}\text { Met or } \\
\text { Exceeded } \\
\text { Goal }\end{array}$ & Exceeded Goal \\
\hline Goal A & 7,095 & $\begin{array}{l}4,436 \\
(62.5 \%)\end{array}$ & $\begin{array}{l}1,623 \\
(22.9 \%)\end{array}$ \\
\hline Goal B & 1,203 & $\begin{array}{l}776 \\
(64.5 \%)\end{array}$ & $\begin{array}{l}274 \\
(22.8 \%)\end{array}$ \\
\hline Goal C & 489 & $\begin{array}{l}92 \\
(18.8 \%)\end{array}$ & $\begin{array}{l}69 \\
(14.1 \%)\end{array}$ \\
\hline Goal D & 2,242 & $\begin{array}{l}562 \\
(25.1 \%)\end{array}$ & $\begin{array}{l}261 \\
(11.6 \%)\end{array}$ \\
\hline Goal E & 318 & $\begin{array}{l}42 \\
(13.2 \%)\end{array}$ & $\begin{array}{l}39 \\
(12.3 \%)\end{array}$ \\
\hline Goal F & 8,834 & $\begin{array}{l}2,186 \\
(24.7 \%)\end{array}$ & 0 \\
\hline Goal G & 796 & $\begin{array}{l}796 \\
(100 \%)\end{array}$ & $\begin{array}{l}192 \\
(24.1 \%)\end{array}$ \\
\hline Total & 20,977 & $\begin{array}{l}8,890 \\
(42.4 \%)\end{array}$ & $\begin{array}{l}2,458 \\
(11.7 \%)\end{array}$ \\
\hline
\end{tabular}

Table 3. Behavioral analysis of student goal attainment

Understanding students' goals enables course designers to change how courses are presented. Since a slim majority of students intended to complete the course, and a significant number wanted to learn one or two new things, we should make it easy for students to find relevant content. Similar to other MOOCs [6], we typically see about half of students who register for a course never return to the course (noshows). Should we therefore offer all course material at the time of registration instead of the typical practice of opening registration several weeks before the course is available? What are other ways we could motivate students to return to the course? Since nearly two-thirds of engaged students want to learn one or two things, we could provide those students with a list of interesting topics addressed in the course with direct links for them to learn about those topics or a way for them to add desired units, lessons, activities, and projects to a custom course.
Along these lines, future work could explore suggesting learning paths based on student goals or encouraging students to create a custom course playlist.

\section{SKILLS AND ACTIVITIES}

The goals of Google's engineering education team, partnering with the Google Maps and Earth teams, include increasing product awareness and adoption through education. The Google course development team speculates that students who gain additional skills for using these products will use them more efficiently and effectively. We therefore wondered whether students gained skills through the course, and if so, did they do so primarily by watching videos, reading text lessons, or completing activities. In the Course Builder platform, Units consist of Lessons; each Lesson can have an optional Activity. In the Mapping with Google course, most lessons consisted of content presented via video and text followed by an interactive activity that asked students to practice the skills presented in the lesson. In three of the lessons $(5.1,5.3$, and 5.4) we linked to existing text or video tutorials and presented an activity instead of a separate video. Activity pages followed lesson pages (and could be reached directly from the left navigation or by clicking a "next" button from the corresponding lesson page). Although course designers intended for students to watch the lesson first and then complete the corresponding activity, students could visit lesson and activity pages in any order.

\section{Methods}

During registration students were presented with a survey asking which behaviors they had done before. Each question mapped to a specific lesson where it was taught and particular questions within an activity. These are indicated in parentheses after each skill below.

How have you used Google Maps in the past?

1. Found a location on a map using the search box in Google Maps (2.1)

2. Obtained directions to a destination (2.2)

3. Viewed reviews for a location on the map (2.3)

4. Saved locations to a custom map (3.1)

5. Shared a map I created with someone else (3.2)

How have you used Google Earth in the past?

6. Downloaded Google Earth (4.1; prerequisite for all activities)

7. Searched for something other than my house in Google Earth (4.1)

8. Turned a layer on or off (4.1)

9. Created a placemark (4.2)

10. Created a tour (4.3) 
11. Shared a placemark or tour with someone else (4.4)

After the course finished, we compared students' skills at the beginning of class with their skills gained through activities during the course. We conducted a clickstream analysis to determine the percentage of students who said they had not used each of these features prior to the class who completed the relevant activities, watched the relevant videos, and completed the final course projects.

\section{Data}

More students completed activities than watched videos or read lesson text. We considered a student to complete an activity if she correctly answered the corresponding application activity questions. Figure 1 compares the number of unique students who viewed lessons (clicked "play" on the relevant video or clicked on the "text version" of the lesson) with the number of unique students who completed the associated activity. We verified with a Wilcoxon signed-rank test that there were significantly more unique students who completed activities than viewed lessons $(\mathrm{p}<0.05)$. Some lessons, like 1.1 and 1.2, are not included here because they did not contain both a lesson and an activity.

We compared the number of students who possessed relevant skills at the beginning of class (per self-report on pre-class questionnaire) who completed final projects. The results are shown in Figure 2.

For each skill, we found differences of less than $1 \%$ in the completion rate; we confirmed that the differences were not significantly different with a paired-sample t-test.

For each skill that had an auto-graded activity, we compared the number of students who completed the relevant activity and the final project. The two groups were confirmed to be significantly different with the pairedsample t-test $(\mathrm{p}<0.01)$. Results are shown in Figure 3.

\section{Discussion}

For 9 of the 12 lessons that contained both video/text lessons and activities, more students completed activities than viewed lesson content. For 3 of the 12 lessons, more students viewed lessons than completed activities. (Note that this does not include data about how long the students viewed videos or stayed on the text lessons.) Our hypothesis is that many students proceeded directly to activities, tried them, and when successful, jumped to the next activity. If unsuccessful, students likely went back to review the video or text lessons. At the time this course was offered, detailed time-stamped clickstream data was not available in Course Builder; we anticipate exploring this specific behavior in future courses.

Students who entered the course without each specific skill

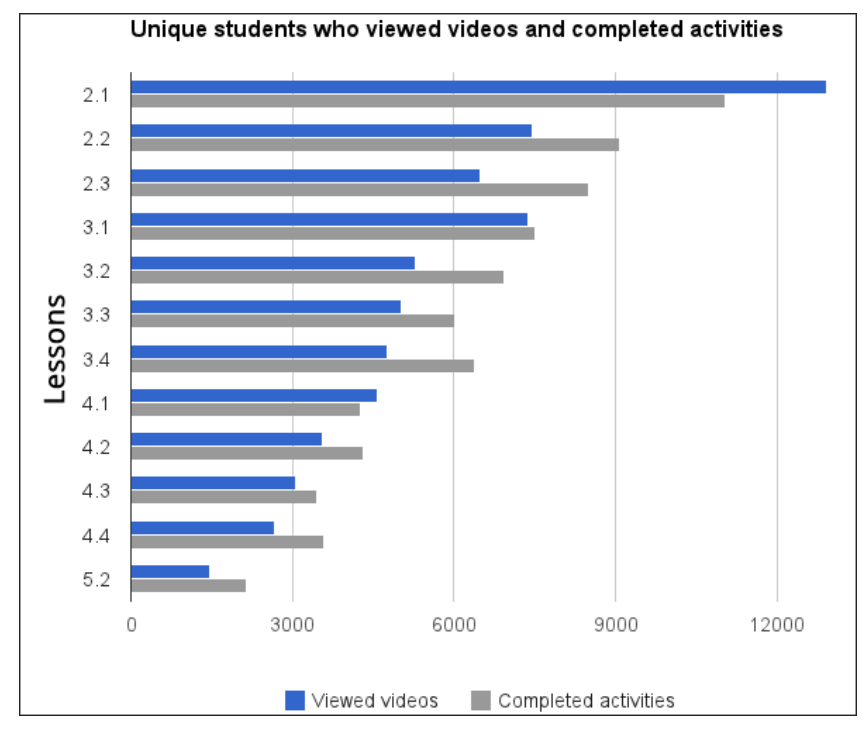

\begin{tabular}{|l|l|l|}
\hline Lesson & Viewed lessons & Completed activities \\
\hline 2.1 & 13,515 & 11,049 \\
\hline 2.2 & 8,112 & 9,082 \\
\hline 2.3 & 6,993 & 8,489 \\
\hline 3.1 & 7,606 & 7,498 \\
\hline 3.2 & 5,664 & 6,939 \\
\hline 3.3 & 5,398 & 6,007 \\
\hline 3.4 & 5,075 & 6,392 \\
\hline 4.1 & 4,742 & 4,270 \\
\hline 4.2 & 3,872 & 4,325 \\
\hline 4.3 & 3,300 & 3,441 \\
\hline 4.4 & 2,943 & 3,588 \\
\hline 5.2 & 1,604 & 2,137 \\
\hline
\end{tabular}

Figure 1. Unique students who viewed lessons and completed activities for each lesson

and completed the activity designed to teach/practice that skill had an overall greater rate of completing the course (as measured by submitting and grading a final project) than students who merely watched videos or clicked on text lessons. This indicates that completing activities, with instant feedback, is an effective way for students to build and assess their skills. It seems that completing activities is a greater predictor of students completing the course than what skills students possess when they enter the course. 


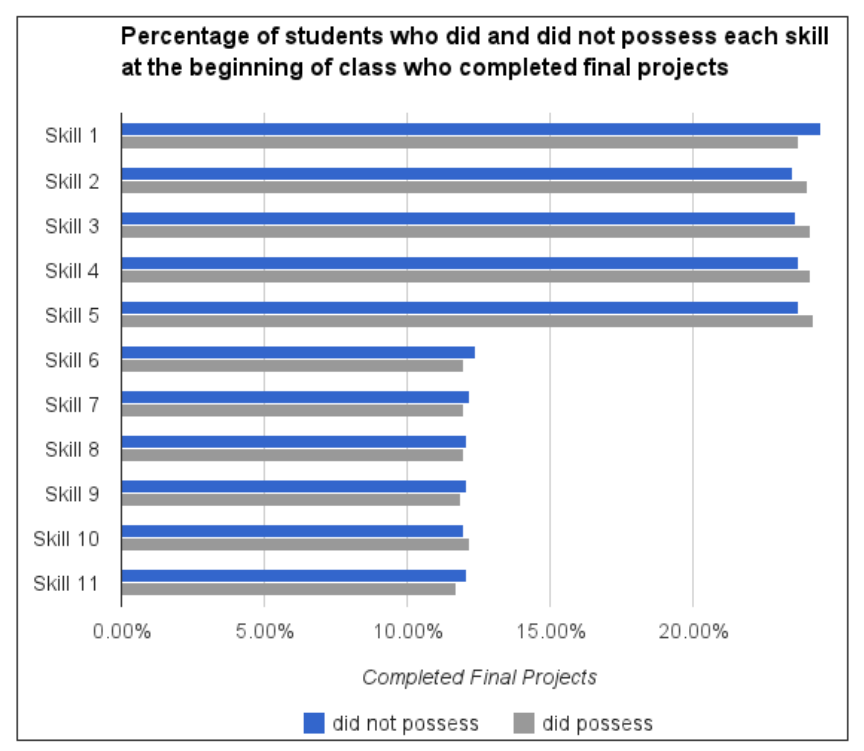

\begin{tabular}{|l|l|l|}
\hline & Did not possess & Did possess \\
\hline Skill 1 & $24.50 \%$ & $23.70 \%$ \\
\hline Skill 2 & $23.50 \%$ & $24 \%$ \\
\hline Skill 3 & $23.60 \%$ & $24.10 \%$ \\
\hline Skill 4 & $23.70 \%$ & $24.10 \%$ \\
\hline Skill 5 & $23.70 \%$ & $24.20 \%$ \\
\hline Skill 6 & $12.40 \%$ & $12 \%$ \\
\hline Skill 7 & $12.20 \%$ & $12 \%$ \\
\hline Skill 8 & $12.10 \%$ & $12 \%$ \\
\hline Skill 9 & $12.10 \%$ & $11.90 \%$ \\
\hline Skill 10 & $12.00 \%$ & $12.20 \%$ \\
\hline Skill 11 & $12.10 \%$ & $11.70 \%$ \\
\hline
\end{tabular}

Figure 2. Percentage of students who possessed each skill at the beginning of class who completed final projects

\section{CONCLUSION}

Students who register for MOOCs have a variety of different goals in mind when they register. Course designers should therefore consider the needs of the audience when designing courses. Courses that do not have high stakes (e.g. count for college credit) could consider making it easy for students to search through the content of a video or course to find and practice specific skills. Even better, why not let students create custom courses that consist of lessons, units, and activities that interest them most? Though overall completion rate may be low, we found significantly higher numbers of students completing their goals than merely completing the course. We believe that simply reporting on completion rates does all of these courses (and students) an injustice, since it ignores the fact that adult learners have varied goals.

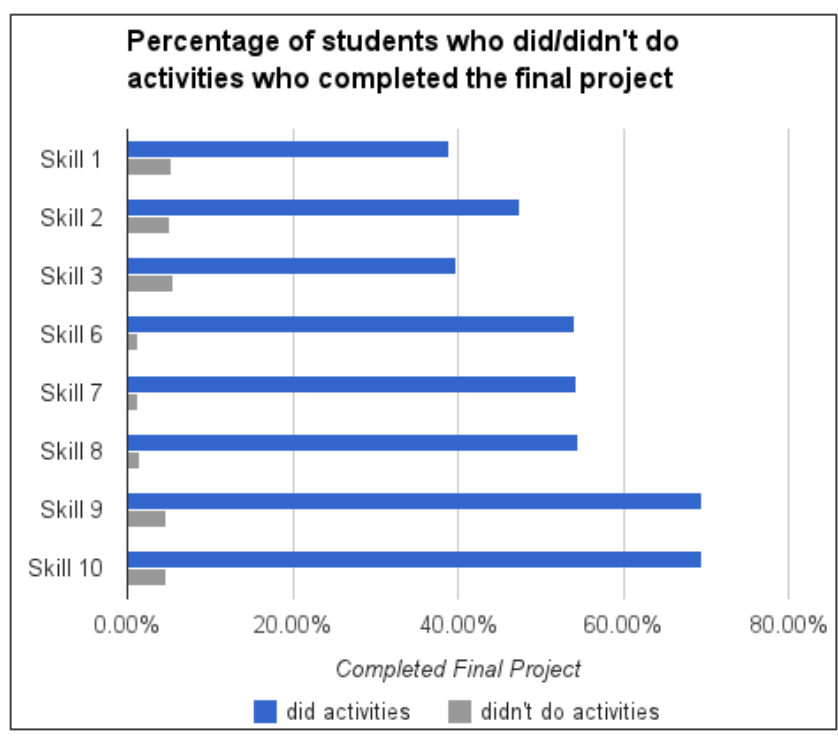

\begin{tabular}{|l|l|l|}
\hline & Did Activities & Didn't Do Activities \\
\hline Skill 1 & $39.01 \%$ & $5.45 \%$ \\
\hline Skill 2 & $47.53 \%$ & $5 \%$ \\
\hline Skill 3 & $39.83 \%$ & $5.51 \%$ \\
\hline Skill 6 & $54.07 \%$ & $1 \%$ \\
\hline Skill 7 & $54.29 \%$ & $1 \%$ \\
\hline Skill 8 & $54.50 \%$ & $1 \%$ \\
\hline Skill 9 & $69.58 \%$ & $4.62 \%$ \\
\hline Skill 10 & $69.58 \%$ & $4.62 \%$ \\
\hline
\end{tabular}

Figure 3. Students who did activities and did not do activities who completed final projects

Future work could involve personalizing courses based on students' goals. How can we motivate students who register but never return to the course? Should we try to inspire casual learners to complete course work? If students want to learn one or two new things, should we make it easier for them to find those new skills by making the entire course available to them at the outset? Perhaps we could retain the feel of the MOOC community by grouping students with similar goals and having them interact with and motivate each other. Future courses could explore different learning paths or different ways of presenting content to students. 
We need to move beyond the one-size-fits-all approach in MOOCs; technology exists that could present different students with different content.

Since more students complete activities than look at lessons, we recommend designing courses (especially technically-oriented courses) more around activities than the traditional lecture. This could involve spending more time developing activities and effective feedback systems as well as physically placing activities before lessons. Students could then test themselves on how well they can complete an activity. If they do not achieve success in the activity, they could then choose to watch the video or read the text lesson, then return to the activity. Although this format will likely work the best for technical courses (including science and math), we believe there is value in starting courses from different disciplines with a practical application of skills taught.

Eventually we hope that courses will adapt or become customized to individual students. One option is to ask students what their goal is and give them a personalized learning path to help them reach that goal. Other personalization options include having students select course elements from a list to create a customized course. In summary, understanding learners' aims and behaviors allows us to create more effective courses for everyone.

\section{ACKNOWLEDGEMENTS}

We thank Alfred Spector, Maggie Johnson, and the Mapping with Google MOOC development team for their advice, feedback, and support. This course utilized Course Builder 1.4.0. [4]. We thank Pavel Simakov and John Cox for continuous support, customizations and advice.

\section{REFERENCES}

1. Block, J. H., and Burns, R. B. 1976. Mastery learning. Review of research in education, 4 (1976), 3-49.

2. Bloom, B. S. 1984. The 2-sigma problem: The search for methods of group instruction as effective as one-toone tutoring. Educational Researcher, 13 (6), 4-16.

3. Breslow, L., Pritchard, D. E., DeBoer, J., Stump, G. S., Ho, A. D., and Seaton, D. T. 2013. Studying learning in the worldwide classroom: Research into edX's first MOOC. Research \& Practice in Assessment 8 (2013), $13-25$.

4. Emanuel, E. J. 2013. Online education: MOOCs taken by educated few. Nature, 503 (7476), 342-342.

5. Google Course Builder. https://code.google.com/p/course-builder/

6. Hill, P. 2013. Emerging Student Patterns in MOOCs: A (Revised) Graphical View [Web log post]. http://mfeldstein.com/

7. Karpicke, J. D., and Blunt, J. R. 2011. Retrieval practice produces more learning than elaborative studying with concept mapping. Science 331 (6018), $772-5$.

8. Kizilcec, R. F., Piech, C., and Schneider, E. 2013. Deconstructing Disengagement: Analyzing Learner Subpopulations in Massive Open Online Courses Categories and Subject Descriptors. In Proc. of the Third International Conference on Learning Analytics and Knowledge (2013), 170-179.

9. Koller, D., Ng, A., Do, C. and Chen, Z. 2013. Retention and Intention in Massive Open Online Courses: In Depth. http://www.educause.edu/

10. Mapping with Google course. 2013. http://mapping.withgoogle.com

11. Parr, C. 2013. Not Staying the Course [Web log post]. www.insidehighered.com.

12. Quillen, I. 2013. Why do students enroll in (but don't complete) MOOC courses? [Web log post]. http://blogs.kqed.org/mindshift

13. Wilkowski, J., Russell, D. M., and Deutsch, A. 2014. Self-evaluation in Advanced Power Searching and Mapping with Google MOOCs. In L@S 2014, Mar 0405 2014, Atlanta, GA, USA. ACM 978-1-4503-26698/14/03. http://dx.doi.org/10.1145/2556325.2566241 